\title{
FIELD MEASUREMENTS ON RUNWAY FRICTION DECAY RELATED TO RUBBER DEPOSITS
}

\author{
Mario De Luca ${ }^{*}$, Francesco Abbondati ${ }^{2}$, Thomas J. Yager ${ }^{3}$, Gianluca Dell'Acqua ${ }^{*}$ \\ 1,2,4 Dept of Civil, Construction and Environmental Engineering, University of Naples Federico II, Italy \\ ${ }^{3}$ Langley Research Center, National Aeronautics and Space Administration (NASA), United States
}

Submitted 29 April 2015; resubmitted 18 November 2015; accepted 23 December 2015

\begin{abstract}
Surfaces of airport pavements are subject to contamination that can be very dangerous for the movement of aircraft particularly on the runway. A recurrent problem is represented by the deposits of vulcanized rubber of aircraft tires in the touchdown area during landings and lesser during take-offs. This causes a loss of grip that compromises the safety of aircraft movements in take-off and landing operations. This study deals with the surface characteristics decay phenomenon related to contamination from rubber deposits. The experiment was conducted by correlating the pavement surface characteristics, as detected by Grip Tester, to air traffic before and after de-rubberizing operation and two models were constructed for the assessment of functional capacity of the runway before and after the operations de-rubberizing.
\end{abstract}

Keywords: airport; runway; rubber deposits; friction, decay curve; grip number; airport pavement management system.

\section{Introduction}

Monitoring the surface characteristics of the runway is a very complex problem for the airport agency. One of the most important and recurrent problem is the contamination phenomena due to rubber deposits. If not properly handled, these occurrences can have serious consequences on the landing and take-off operations, compromising significantly their safety (Čokorilo et al. 2014). In recent years, many researchers have proposed several solutions for the control and management of these particular phenomena that can compromise runway pavement friction (Yager 2009).

Chen et al. (2008) focused an important factor that affects the available friction on a runway: the amount of rubber deposits on the pavement surface. Rubber deposits occurring at the touchdown area on runways can be quite extensive. Heavy rubber deposits may completely cover the pavement surface texture and cause loss of aircraft braking capability and directional control when runways are wet.

Suh et al. (2002) developed mathematical prediction models for the deterioration of rigid airfield pavements in South Korea. To derive the models, an integrated database of pavement conditions, age, traffic volume, and other characteristics was assembled. From the validation plots, the pavement condition indexes (PCIs) predicted were in good agreement with the measured PCIs. Results from the independent data demonstrated an acceptable degree of accuracy of the models.

Wambold et al. (2003) report of the Joint Winter Runway Friction Measurement Program between the National Aeronautics and Space Administration (NASA), Transport Canada (TC), and the Federal Aviation Administration (FAA): the program performed instrumented aircraft and ground vehicle tests aimed at identifying a common number that all the different ground vehicle devices would report. This number, denoted as the International Runway Friction Index (IRFI), will be related to all types of aircraft stopping performance.

This paper describes an experimental study on runway pavement friction decay related to rubber deposits at the Lamezia Terme International Civil Airport located in Italy. The three years long experiment, from 2010 to 2012, was conducted by correlating the pavement surface characteristics, as detected by Grip Tester, to air traffic before and after de-rubberizing operation and two empirical friction decay models as function of aircraft loads were constructed for the assessment of functional capacity of the runway. 


\section{Data Collection}

\subsection{Lamezia Terme Airport}

The International Civil Airport of Lamezia Terme (Fig. 1) is equipped with a $4 \mathrm{D}$ class runway named RWY $10 / 28$ of approximately $145000 \mathrm{~m}^{2}$, built with flexible pavement whose structural characteristics are identified by the code: PCN 58/F/B/W/T.

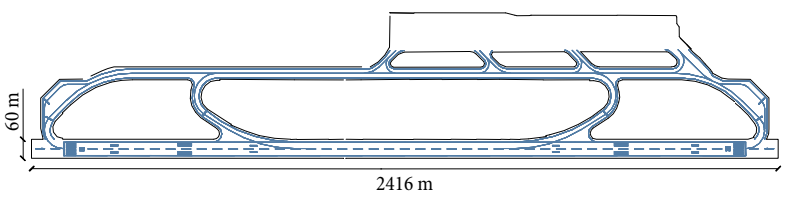

Fig. 1. Airside: runway, taxiway, and ramps

Runway has magnetic orientation $96-276^{\circ}$, length $2416 \mathrm{~m}$ and width $60 \mathrm{~m}$.

Geographic coordinates and altitude on the average sea level are as follows:

- latitude: $38^{\circ} 54^{\prime} 30^{\prime \prime}$ North;

- longitude: $16^{\circ} 14^{\prime} 30^{\prime \prime}$ East;

- altitude: $12.31 \mathrm{~m}$ on the a.s.l.

The runway has a flexible pavement with a dense asphalt-wearing surface. The different layers and materials making up the pavement of the runway are as follows:

- first layer (surface): $4 \mathrm{~cm}$ in dense asphalt;

- second layer (binder): $4 \mathrm{~cm}$ in dense asphalt;

- third layer (base): $18 \mathrm{~cm}$ in dense asphalt;

- fourth layer (sub-base): $20 \mathrm{~cm}$ in concrete;

- fifth layer (subgrade): $40 \mathrm{~cm}$ in 'mixed crushed rock'.

The thickness data are the same, on average, for all the runway area.

The upper pavement layer (surface) has been put in place in 2004 and the operations of de-rubberizing, in the area of touchdown, were performed in July 2007 and November 2011.

\subsection{Survey of Surface Characteristic}

The surface characteristic of the runway (Thenoux et al. 1996; Najafi et al. 2013) has been detected by the Grip Tester according to ICAO-Doc.9137-AN/898 (Fig. 2). For more information on pavement surface texture and how tire friction performance can be improved, see references (Horne et al. 1968; Yager 1983; De Luca, Dell'Acqua 2014; Leland et al. 1968). In both runway touchdown areas, the Grip Tester friction (Grip Number - GN) measurements (De Luca et al. 2015) were collected along six alignments as shown in Fig. 3 following the time line schedule given in Table 1.

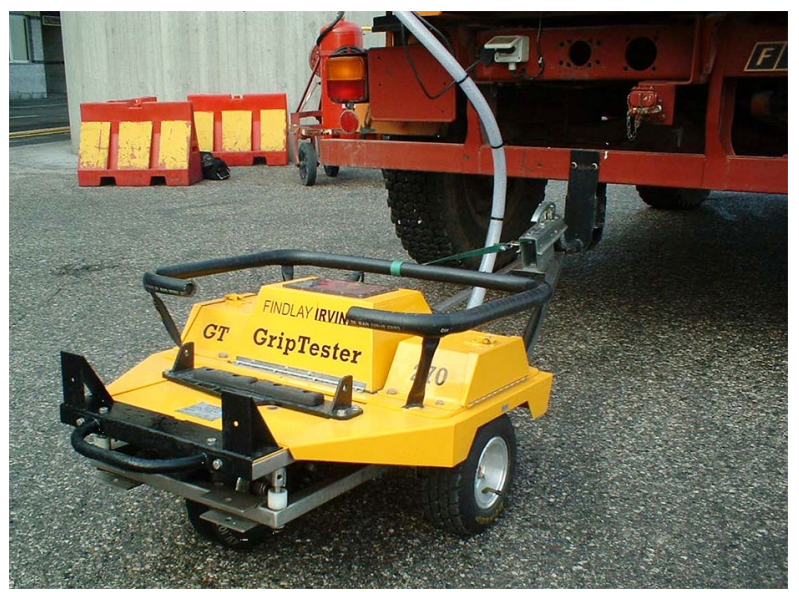

Fig. 2. Grip Tester

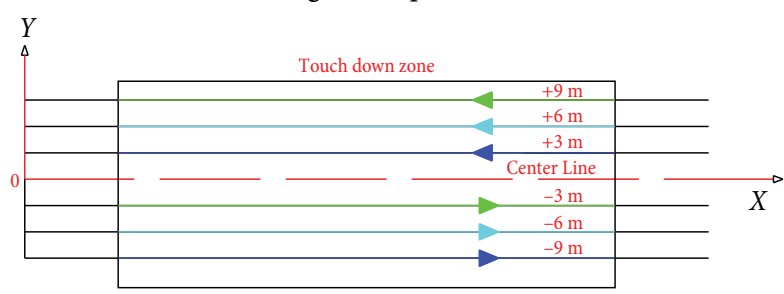

Fig. 3. Layout of GN survey

Table 1. GN surveys timetable before and after runway de-rubberizing

\begin{tabular}{|l|l|c|c|}
\hline \multicolumn{1}{|c|}{ Surveys time } & \multicolumn{1}{|c|}{ Runway status } & Measured parameter & Number of surveys \\
\hline From 1 January 2010 to 30 June 2011 & Before de-rubberizing & GN & 10 \\
\hline From 1 November 2011 to 31 December 2012 & After de-rubberizing & GN & 6 \\
\hline
\end{tabular}

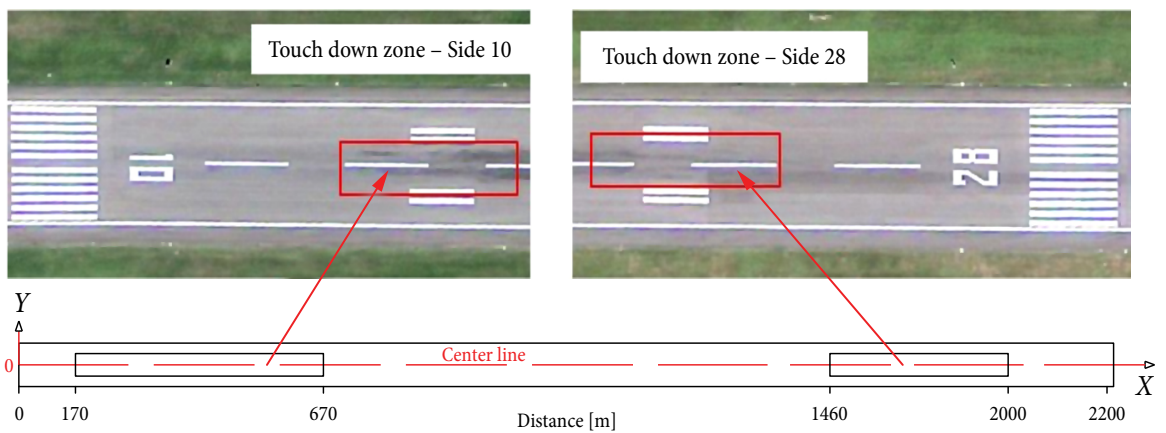

Fig. 4. Touchdown zones before de-rubberizing made in November 2011 
In particular, the measurements were taken in the area with rubber deposits at the following distances from the side 10 of the runway (Fig. 4):

- from $170 \mathrm{~m}$ to $670 \mathrm{~m}$;

- from $1460 \mathrm{~m}$ to $2000 \mathrm{~m}$.

\subsection{Air Traffic Data Providing and Organization}

Traffic data relating to flights that occurred from 1 January 2010 to 31 December 2012 was provided by the Airport 'post-holder' office (Table 2).

The spectrum of aircrafts traffic is given in Fig. 5.

To define the loads acting on the runway due to the transit of aircraft, the following relationship was used:

$$
\begin{aligned}
& L=\left(\left(\frac{T W}{A_{\text {WGtake-off }} \cdot N_{W G}}\right)+\right. \\
& \left.\left(\frac{L W}{A_{\text {WGlanding }} \cdot N_{W G}}\right)\right) \cdot A_{t, l},
\end{aligned}
$$

where: TW (Take-off Weight) - take-off aircraft weight $[\mathrm{N}]$, it was assumed to be equal to $70 \%$ of real weight (the load is reduced because there is the thrust due to the lift); $L W$ (Landing Weight) - landing aircraft weight [N], it was assumed to be equal to $70 \%$ of real weight (the load is reduced because there is the thrust due to the lift); $A_{\text {WGtake-off }}$ - trace area of a main landing-gears wheel at take-off $\left[\mathrm{m}^{2}\right]$, defined as:

$$
A_{\text {WGtake-off }}=\frac{L_{W G \text { take-off }}}{P_{W G}} ;
$$

$L_{\text {WGtake-off }}$ - load on a wheel at take-off $[\mathrm{N}] ; P_{W G}-$ main landing-gears tires inflation pressure $\left[\mathrm{N} / \mathrm{m}^{2}\right]$; $A_{\text {WGlanding }}$ - trace area of a main landing-gears wheel at landing $\left[\mathrm{m}^{2}\right]$, defined as:

$$
A_{\text {WGlanding }}=\frac{L_{W G l a n d i n g}}{P_{W G}} ;
$$

$L_{W G \text { landing }}$ - load on a wheel at landing [N]; $P_{W G}-$ as above mentioned $\left[\mathrm{N} / \mathrm{m}^{2}\right] ; N_{W G}$ - total number of all main landing-gears wheels; $A_{t, l}$ - area where the $99 \%$ of aircraft has made the operation of touchdown or takeoff $\left[\mathrm{m}^{2}\right]$; it was considered a strip of $18 \mathrm{~m}$ (assuming the centreline as the axis) and a length of $1040 \mathrm{~m}$.

Rubber deposits produced from nose tire touchdown have been ignored.

For each aircraft, landing or in take-off, the load induced on the runway was calculated through Eq. (1). The cumulative load $L_{c}$ [expressed in $\mathrm{Gt}=10^{13} \mathrm{~N}$ ] of the three years 2010, 2011 and 2012 was obtained as cumulative sum of all loads $L[\mathrm{~N}]$ from 1 January 2010 to 31 December 2012. Fig. 6 shows the trend of the cumulative load in the three years.

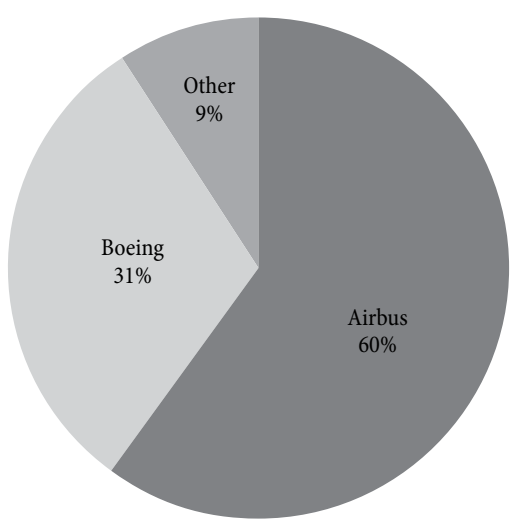

Fig. 5. Spectrum of aircrafts traffic

\begin{tabular}{|c|c|c|c|c|c|c|c|c|c|}
\hline Date & Aircraft type & $\mathrm{TW}[\mathrm{t}]$ & $\mathrm{LW}[\mathrm{t}]$ & $L_{\text {WGtake-off }}[\mathrm{t}]$ & $L_{\text {WGlanding }}[\mathrm{t}]$ & $A_{\text {WGtake-off }}\left[\mathrm{m}^{2}\right]$ & $A_{\text {WGlanding }}\left[\mathrm{m}^{2}\right]$ & Type gear & $N_{W G}$ \\
\hline$\ldots$ & $\ldots$. & $\ldots$ & $\ldots$ & $\ldots$ & $\cdots$ & $\cdots$ & $\cdots$ & $\cdots$ & $\cdots$ \\
\hline \multirow{9}{*}{24 June 2010} & A 320 & 84.4 & 82.8 & 21.10 & 20.70 & 0.159 & 0.156 & Tandem & 4 \\
\hline & A 320 & 83.8 & 83.2 & 20.95 & 20.80 & 0.158 & 0.156 & Tandem & 4 \\
\hline & A 320 & 82.8 & 81.6 & 20.70 & 20.40 & 0.156 & 0.153 & Tandem & 4 \\
\hline & A 321 & 97.4 & 95.1 & 24.35 & 23.78 & 0.175 & 0.171 & Tandem & 4 \\
\hline & В 734 & 72.8 & 71.3 & 18.20 & 17.83 & 0.128 & 0.126 & Tandem & 4 \\
\hline & В 737 & 72.1 & 66 & 18.03 & 16.50 & 0.119 & 0.109 & Tandem & 4 \\
\hline & B 737 & 75.8 & 75.6 & 18.95 & 18.90 & 0.125 & 0.124 & Tandem & 4 \\
\hline & В 737 & 71.7 & 69.4 & 17.93 & 17.35 & 0.118 & 0.114 & Tandem & 4 \\
\hline & MD 82 & 69.5 & 68.3 & 17.38 & 17.08 & 0.138 & 0.136 & Tandem & 4 \\
\hline$\ldots$. & $\ldots$. & $\ldots$ & $\ldots$ & $\ldots$ & $\ldots$ & $\ldots$ & $\ldots$ & $\ldots$ & $\ldots$ \\
\hline
\end{tabular}

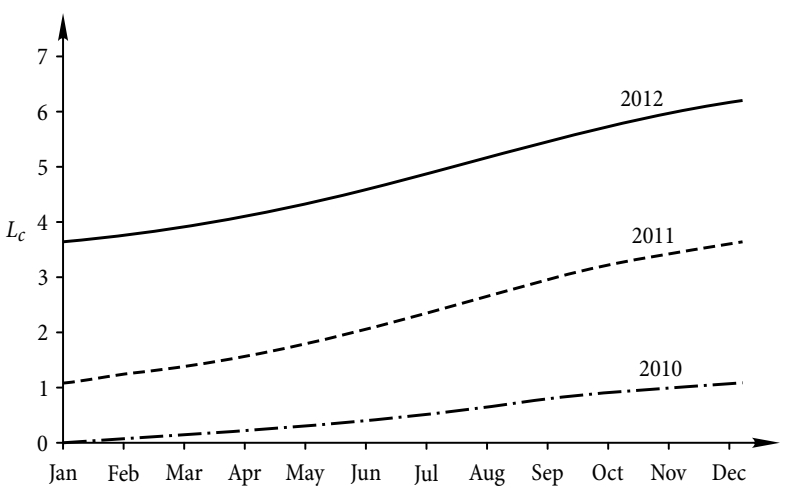

Fig. 6. Cumulative load $L_{c}[\mathrm{Gt}]$

Table 2. Sample data excerpt from air traffic sequence on runway 10/28 


\section{Data analysis}

\subsection{Data Analysis before De-Rubberizing Operations}

The GN detected with the Grip Tester, according to the calendar shown in Table 1, before the de-rubberizing operations, was organized in 25 classes with the same width of 0.03 in $\Delta G N$ (Table 3). 25 is the number of classes that produced the best statistically model (i.e. the higher coefficient of determination $\rho^{2}$ and the significance at 95\%).

Subsequently, through a multivariate regression analysis (GN as the dependent variable and $L_{c}$ as the predictor), model (2) was obtained:

$$
G N=b_{1}+e^{b_{2} \cdot L_{c}} .
$$

$\rho^{2}=0.69$; coefficient and confidence interval of model (2) are shown in Table 4.

Table 3. GN classes before de-rubberizing

\begin{tabular}{|c|c|c|}
\hline Class & GN & $L_{c}[\mathrm{Gt}]$ \\
\hline 1 & 0.94 & 1.00 \\
\hline 2 & 0.91 & 1.00 \\
\hline 3 & 0.88 & 1.00 \\
\hline 4 & 0.85 & 1.04 \\
\hline 5 & 0.82 & 1.27 \\
\hline 6 & 0.79 & 1.41 \\
\hline 7 & 0.76 & 1.46 \\
\hline 8 & 0.73 & 2.02 \\
\hline 9 & 0.70 & 3.07 \\
\hline 10 & 0.67 & 3.34 \\
\hline 11 & 0.63 & 3.54 \\
\hline 12 & 0.60 & 3.57 \\
\hline 13 & 0.57 & 3.35 \\
\hline 14 & 0.55 & 2.29 \\
\hline 15 & 0.51 & 2.61 \\
\hline 16 & 0.48 & 2.91 \\
\hline 17 & 0.45 & 3.10 \\
\hline 18 & 0.42 & 3.10 \\
\hline 19 & 0.39 & 3.02 \\
\hline 20 & 0.36 & 3.23 \\
\hline 21 & 0.33 & 3.31 \\
\hline 22 & 0.29 & 3.37 \\
\hline 23 & 0.26 & 3.39 \\
\hline 24 & 0.24 & 3.48 \\
\hline 25 & 0.20 & 3.71 \\
\hline
\end{tabular}

Table 4. Coefficient and confidence interval of model (2)

\begin{tabular}{|c|c|c|c|c|}
\hline \multirow{2}{*}{ Parameter } & \multirow{2}{*}{ Estimate } & \multirow{2}{*}{$\begin{array}{c}\text { Std. } \\
\text { error }\end{array}$} & & \multicolumn{2}{|c|}{$95 \%$ confidence interval } \\
\cline { 4 - 5 } & & & Lower bound & Upper bound \\
\hline$b_{1}$ & 0.240 & $0.4 \backslash 04$ & -0.595 & 1.076 \\
\hline$b_{2}$ & -0.467 & 0.572 & -1.651 & 0.717 \\
\hline
\end{tabular}

\subsection{Data Analysis after De-Rubberizing Operations}

The GN detected with the Grip Tester, according to the calendar shown in Table 1, after the de-rubberizing operations, was organized into 17 classes with the same width of 0.03 in $\Delta \mathrm{GN}$ (Table 5 ). 17 is the number of classes that produced the best statistically model (i.e. the higher coefficient of determination $\rho^{2}$ and the significance at $95 \%)$.

Through a multivariate regression analysis (GN as the dependent variable and $L_{c}$ as the predictor), then model (3) was obtained:

$$
G N=b_{1} \cdot e^{b_{2} \cdot L_{c}}
$$

$\rho^{2}=0.83$; coefficient and confidence interval of model (3) are shown in Table 6.

\begin{tabular}{|c|c|c|}
\hline Class & GN & $L_{c}[\mathrm{Gt}]$ \\
\hline 1 & 0.75 & 3.89 \\
\hline 2 & 0.72 & 3.75 \\
\hline 3 & 0.69 & 3.93 \\
\hline 4 & 0.66 & 3.86 \\
\hline 5 & 0.63 & 3.84 \\
\hline 6 & 0.60 & 3.83 \\
\hline 7 & 0.57 & 3.91 \\
\hline 8 & 0.54 & 4.44 \\
\hline 9 & 0.51 & 4.25 \\
\hline 10 & 0.48 & 4.30 \\
\hline 11 & 0.44 & 4.05 \\
\hline 12 & 0.41 & 4.23 \\
\hline 13 & 0.38 & 4.58 \\
\hline 14 & 0.35 & 4.68 \\
\hline 15 & 0.32 & 5.01 \\
\hline 16 & 0.29 & 4.93 \\
\hline 17 & 0.26 & 4.97 \\
\hline
\end{tabular}

Table 5. GN classes after de-rubberizing

Table 6. Coefficient and confidence interval of model (3)

\begin{tabular}{|c|c|c|c|c|}
\hline \multirow{2}{*}{ Parameter } & \multirow{2}{*}{ Estimate } & \multirow{2}{*}{$\begin{array}{c}\text { Std. } \\
\text { error }\end{array}$} & & \multicolumn{2}{|c|}{$95 \%$ confidence interval } \\
\cline { 4 - 5 } & & & Lower bound & Upper bound \\
\hline$b_{1}$ & 9.58 & 3.554 & 2.008 & 17.160 \\
\hline$b_{2}$ & -0.698 & 0.091 & -0.892 & -0.504 \\
\hline
\end{tabular}

\subsection{Before-After De-Rubberizing Analysis}

It is well known, that a good preventive maintenance allows the runway to have a good lifecycle. See for example a pavement decay curve with a proper preventive maintenance proposed in Fig. 7.

The rubberizing phenomenon in the areas of touchdown, if there are no periodic preventive maintenance actions, causes a sudden deterioration of the performance of the runway in terms of GN. In this regard, 
the Decay curve with preventive maintenance in Fig. 7 shows how a simple act of de-rubberizing in the touchdown zone, can bring the pavement surface to acceptable values of GN.

Specifically for this study, through the models (2) and (3) obtained in the previous paragraphs, it is possible to assess the degree of the benefit due to the action of de-rubberizing. Through Eq. (2), whose trend is shown in Fig. 8 (valid for values of cumulative load $L_{c}$ belonging to the interval $[1.00,3.71])$, it's possible to estimate the curve before de-rubberizing; through the Eq. (3), whose trend is shown in Fig. 9 (valid for values of cumulative load $L_{c}$ belonging to the interval $[3.75,5.01]$ ), it's possible to estimate the curve after de-rubberizing.

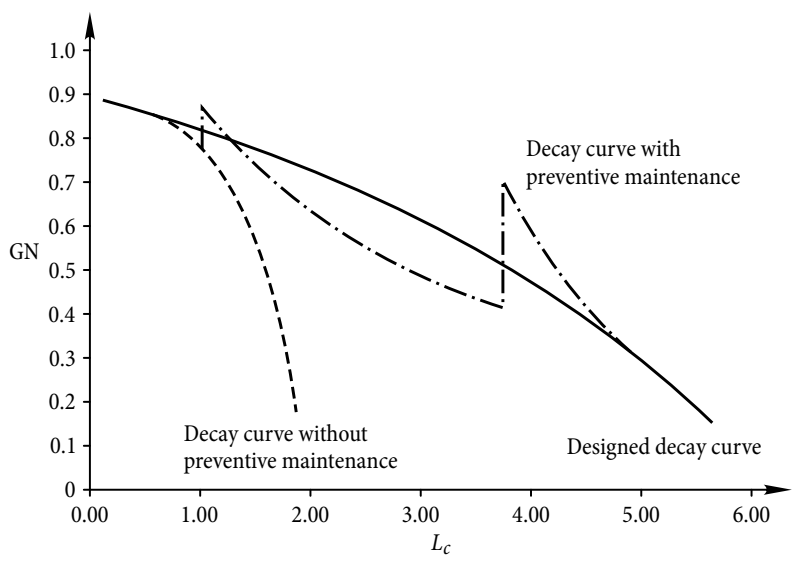

Fig. 7. Pavement decay curves

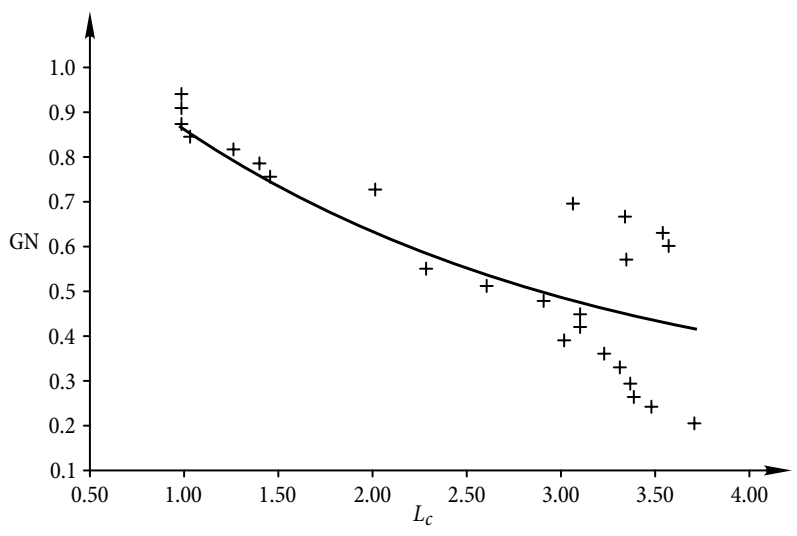

Fig. 8. GN versus $L_{c}$ decay before de-rubberizing

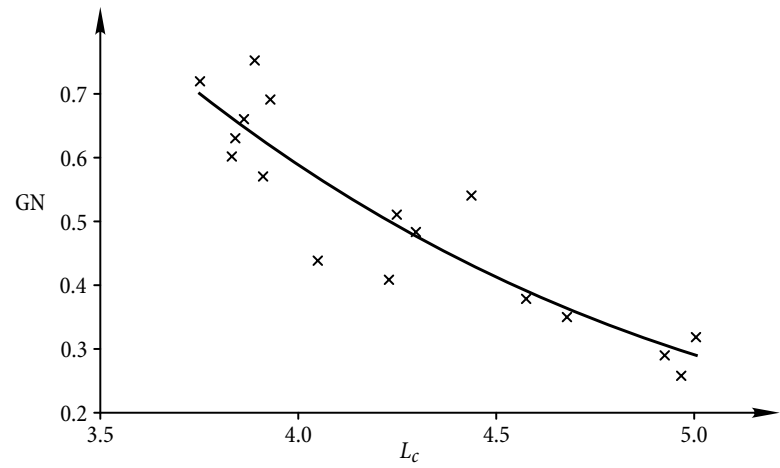

Fig. 9. GN versus $L_{c}$ decay after de-rubberizing

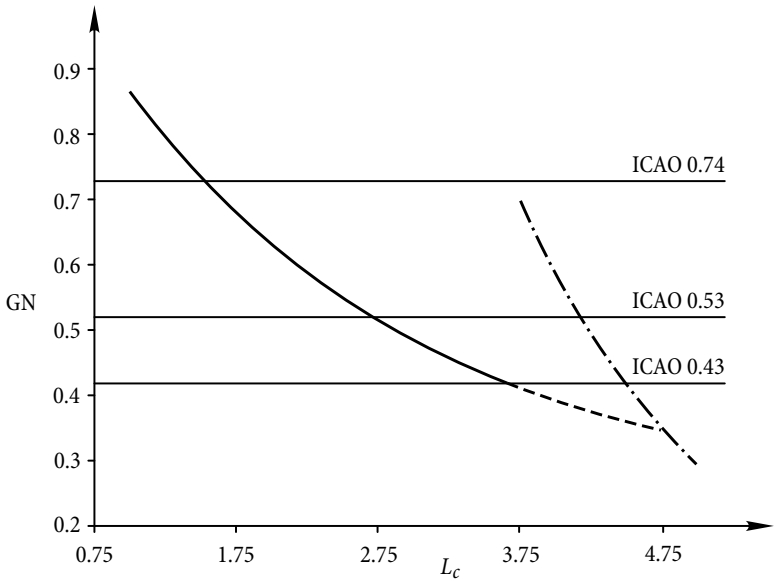

Fig. 10. GN: before-after decay

From the comparison of the two trends (Fig. 10) it can be evaluated as well as the benefit of degumming in terms of GN, also important information about the slope of the two curves; in fact, the second dashed curve GN after decreases faster than the first solid curve GN before. An explanation for this phenomenon of faster decrease of the curve GN After could be that the aggregates, even if the layers of rubber are cleaned up, are subjected to stress that compromises their structural and functional characteristics.

\section{Conclusions}

In this paper, a comparison was made between the functional characteristics of the runway before and after the operations of de-rubberizing.

In particular, in the touchdown areas, air traffic and GN (measured by Grip Tester) data were examined before de-rubberizing operations (from 1 January 2010 to 30 November 2011) and after de-rubberizing operations (from 1 November 2011 to December 31, 2012) and two models of decay as function of aircraft loads were obtained (Figs 8 and 9 ) characterized by good significance $(p<0.05)$ and by good coefficient of determination.

The comparison of the two models highlighted also that, even if the operations of de-rubberizing reported higher values of GN, the decay in the touchdown areas was characterized by greater speed than that before the de-rubberizing operation (Fig. 10).

The obtained models demonstrate that it is possible to predict with great accuracy the phenomenon of surface decay on the basis of air traffic and aircraft parameters, and how to do it. And therefore their usefulness as tools to design and update the Airport Pavement Management Systems, to plan maintenance operations, and to forecast the life cycle of runway pavement surface.

\section{Acknowledgements}

The authors would also like to acknowledge the Lamezia Terme International Airport staff for providing information related to this study and the airfield professionals who shared their insight on the state-of-the-practice of runway friction measurement. 


\section{References}

Chen, J.-S.; Huang, C.-C.; Chen, C.-H.; Su, K.-Y. 2008. Effect of rubber deposits on runway pavement friction characteristics, Transportation Research Record: Journal of the Transportation Research Board 2068: 119-125. http://doi.org/10.3141/2068-13

Čokorilo, O.; De Luca, M.; Dell'Acqua, G. 2014. Aircraft safety analysis using clustering algorithms, Journal of Risk Research 17(10): 1325-1340.

http://doi.org/10.1080/13669877.2013.879493

De Luca, M.; Abbondati, F.; Dell'Acqua, G.; Yager T. J.; Coraggio, G. 2015. Pavement friction decay: preliminary study in Lamezia Terme International Airport, Italy, in TRB 94th Annual Meeting Compendium of Papers, 11-15 January 2015, Washington, DC, 1-14.

De Luca, M.; Dell'Acqua, G. 2014. Runway surface friction characteristics assessment for Lamezia Terme airfield pavement management system, Journal of Air Transport Management 34: 1-5.

http://doi.org/10.1016/j.jairtraman.2013.06.015

Horne, W. B.; Yager, T. J.; Taylor, G. R. 1968. Review of Causes and Alleviation of Low Tire Traction on Wet Runways, NASA Technical Note NASA-TN-D-4406. 39 p. Available from Internet: http://ntrs.nasa.gov/search.jsp?R=19680010151

ICAO-Doc.9137-AN/898. Airport Services Manual.

Leland, T. J. W.; Yager, T. J.; Joyner, U. T. 1968. Effects of Pavement Texture on Wet-Runway Braking Performance, NASA Technical Note NASA-TN-D-4323. 40 p.

Najafi, S.; Flintsch, G. W.; McGhee, K. K. 2013. Assessment of operational characteristics of continuous friction measuring equipment (CFME), International Journal of Pavement Engineering 14(8): 706-714. http://doi.org/10.1080/10298436.2012.667097

Suh, Y.-C.; Park, D.-Y.; Jeong, K.-Y. 2002. Development of deterioration prediction models for airfield rigid pavements, Transportation Research Record: Journal of the Transportation Research Board 1788: 132-137. http://doi.org/10.3141/1788-17

Thenoux, G.; Allen, W.; Bell, C. 1996. Study of aircraft accident related to asphalt runway skid resistance, Transportation Research Record: Journal of the Transportation Research Board 1536: 59-63. http://doi.org/10.3141/1536-09

Yager, T. J. 2009. Runway friction measurement status, International Airport Review (1). Available from Internet: http:// www.internationalairportreview.com

Yager, T. J. 1983. Factors Influencing Aircraft Ground Handling Performance. NASA Technical Memorandum NASATM-85652. 31 p. Available from Internet: http://ntrs.nasa. gov/?R=19830019708

Wambold, J. C.; Yager, T. J.; Boccanfuso, A. 2003. Joint winter runway friction program accomplishments, in The XXIInd PIARC World Road Congress, 19-25 October 2003, Durban, South Africa, 1-14. 